\title{
Open Fun Football Schools
}

During the summer of 2009, Cross Cultures educated more than 3,000 voluntary leaders and trainers specifically for our Open Fun Football Schools program through regional seminars lasting 3-5 days. With a further 3,000 volunteer trainer assistants, these volunteers organized 154 Open Fun Football Schools for about 30,000 girls and boys aged 7 to 11 years in 12 countries in the Balkan, Trans-Caucasus (including Moldova) and the Middle East regions.

Adding the large number of children participating Cross Cultures' one-day-fun-football-festivals, municipal authorities involved as well as the parents of the children, the Open Fun Football School programme was communicating directly with over 100,000 people.

Today Cross Cultures is considered among the world leading organizations specialized in using the development of sport and children's grassroots football as a tool to foster peaceful relations, gender equality, tolerance, and social cohesion between people living in post conflicting areas. This essay provides a personal perspective of the football program's development from its inception to what it is today - a humanitarian organization and movement in The Balkans and Trans-Caucasus region.

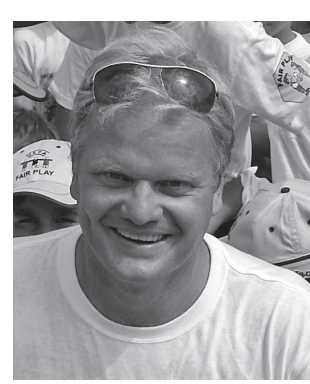

BY

ANDERS

LEVINSEN

\section{THE FOOTBALL SCHOOL'S EMERGENT START}

It was not my intention or my ambition to build Cross Cultures. I wanted to use the Danish Football Association (DBU), and more specifically its summer football school concept as a tool in the reconciliation and reintegration process in Bosnia Herzegovina. At the same time it was a personal project.

I was quite young when I served the UNHCR emergency operation in the Former Yugoslavia (1992-93). In this setting I found myself charged with lots of responsibilities, amongst others I 
was the Head of the UN emergency operation in central and North-Eastern Bosnia Herzegovina, setting up and coordinating an emergency operation for more than 780,000 beneficiaries per month. As Head of the UN lead agency, I was also charged with the responsibility to develop and coordinate the cooperation between the civil UN Agencies and the military forces (UNPROFOR) in my AOR (area of responsibility). I found myself negotiating several local peace talks. I was arrested by militant groups involved in the war, and shot at by snipers in Sarajevo and Central Bosnia. Not least, I saw the horror of several massacres. When I returned to Denmark, I used a few years of my life and that of my family, lying on the sofa feeling sorry for myself and mulling over my experiences.

I was burnt out when I left the emergency operation, and to recover I had a personal need to return and be with old friends. I wanted to get a feeling for the peace process and to close that personal chapter of my life. However, today I feel privileged as I sit in my living room - 12 years later - holding a copy of a letter that I wrote to our volunteer leaders back in 1998, in which I thanked them for their invaluable input and encouraged them to move the project forward, if football schools were to have a future in their country. I needed to move on with my life.

Fortunately, that was not to be. My good friend and colleague, Esad Hadzijusofovic, called me when he received my letter and said that, under no circumstances, was I to withdraw from the project because the football schools provided meaningful activities that were needed by the country.

\section{CONFLICTS AND WAR}

If you have once lived in a war zone, you will know that war and violently conflicts have their own dynamics. In Bosnia Herzegovina (1992-93), I witnessed first-hand how the violence escalated from nothing to utter madness, tearing the country and its people apart.

The Bosnian war was so-called asymmetric warfare as there were multiple fronts entailed guarded by the different ethnic group soldiers. It was a civil war that first and foremost took place behind these fronts, with means the world would come to know as "ethnic cleansing". It was a war in which men of power used violence, fear, hate and chauvinistic nationalism as a means of driving out minority groups and gaining full control over a specific territory - a means that raised the most destructive feelings, dug deep divisions between belligerents, and brought conflicts to escalation with more revenge, violence, barbarism, and destruction.

Just like the famous snowball, violence and conflict grew increasingly over time in Bosnia Herzegovina. The war and violence had its own dynamics that were founded on feelings of fear, hatred and revenge - feelings that nurtured chauvinistic nationalism. And that was my very real experience when the war first broke out with its concrete actions and violence. The "national war psychosis" played a larger role in the war and its development put an end to the ethnic, historical or religious reasons that were voiced as the rationale for the dispute.

In Bosnia Herzegovina I learned that conflict resolution and humanitarian assistance was not only about distributing food and other forms of aid to the war victims. If one wished to use humanitarian assistance proactively as a means to resolve conflict, as an aid worker one had to use this assistance as a means to counteract the violence and demonizing and to make life as difficult as possible for the offensive militants. One way of doing this, for example, is by establishing 
distribution systems, undertaking projects and building structures that aim to build bridges and ties amongst people and victims from the divided population groups.

\section{THE OPEN FUN FOOTBALL SCHOOL CONCEPT}

The concept of the Open Fun Football School is built on the experience of what war is and the extent to which war and violence segregate people. Despite the fact that peace talks may be ongoing, that diverse check-points are being torn down, and soldiers are retreating from the front lines, the war's horrors, anxiety and demons still consume the people's hearts. We all can remember that place and that situation where the snipers or the enemy tried to fire at us. We all can remember the specific conditions during the war that are associated with concrete situations and places and that still raise fear in us when we revisit them.

The purpose of the Open Fun Football Schools is to use our football school concept and pedagogy with the aim to "build bridges and ties" - friendship and collaboration in sports - between children and adults from the various population groups who live segregated from each other because of war and conflicts. We want to use the football schools as a tool for reconciliation between children and adults from divided communities.

\section{A DECISIVE OCCURRENCE...}

There have been many landmark situations that have had decisive impact on the Open Fun Football Schools and on our success.

During the summer of 1999, we were contacted by some Bosnian Serbs who were displeased with the fact that we had not planned any football schools in the Serbian part of Sarajevo. We of course understood their viewpoint and decided to organize an extra Open Fun Football
School in the Serbian part of Sarajevo - Lukavica. However, there would be one condition. The football school would have to maintain a balance with respect to the participating children and trainers - they were to come from both the Muslim and Serbian parts of the city.

When the day came to start the football school, we went out to greet the children and the volunteer trainers. We expected to see 200 boys and girls in their team caps and T-shirts in full activity out on the field with their volunteer trainers. That was not the scenario that awaited us. There were 200 children on the field running around but they were running in one large mass towards the same four footballs. The children had not been given their school T-shirts, and worse still, all of the volunteer trainers were sitting around the table at a nearby café drinking coffee and slivovic. I was enraged until the school leader took me by the arm and said "Take it easy, Anders! When we met up this morning to prepare the field we became aware that just four years earlier these same trainers were on separate sides of the frontline and shot at each other. They recognized each other by their

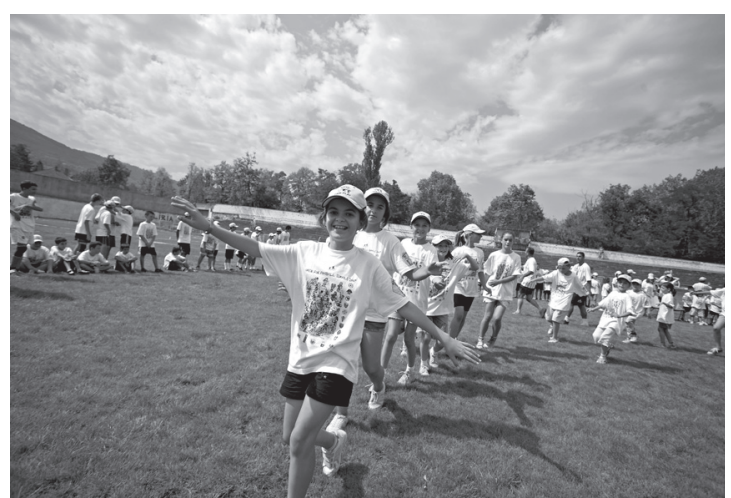

Bosnia and Herzegovina, Open Fun Football School (Photo: Fedja Krvavac). 


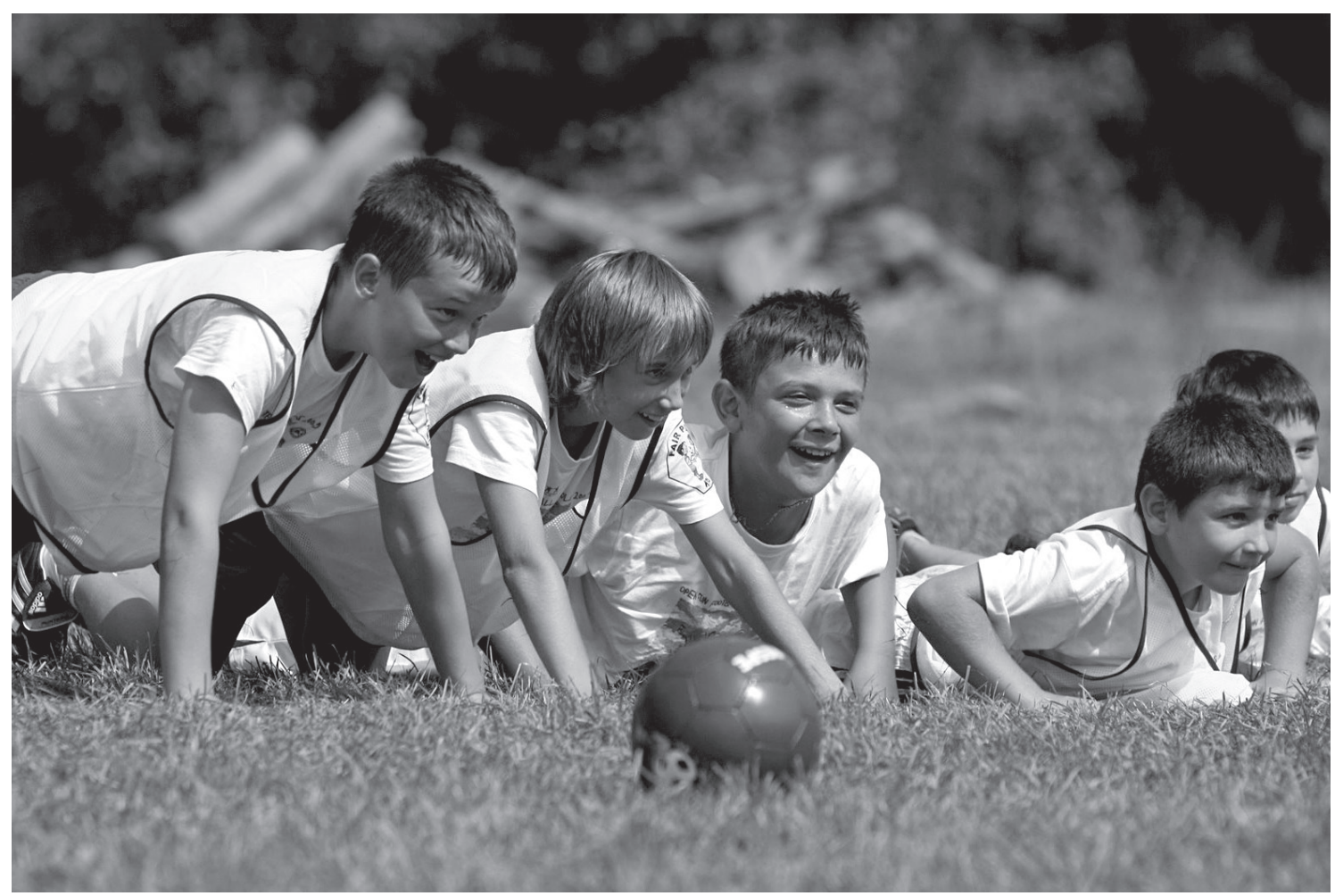

Bosnia and Herzegovina, Open Fun Football School (Photo: Fedja Krvavac).

voices!" The school leader therefore felt that it was more constructive to start the day with a reconciliation snaps at the café.

We headed toward the café and drank a cup of coffee with the trainers while we introduced them to our trainers' manual. After that, we went out to where the children had gathered and launched the football school. From a technical perspective it probably was not the most sophisticated school we have organized, however, it became a fantastic school with a very special atmosphere. First of all, the trainers danced around the playing field crosswise with the children in long rows. For another, it could be considered the most frequented football school we had established to date.

Each day, more and more of our volunteer trainers came to the football school from "the other side". They had no assigned position as a leader or trainer but they congregated in small groups in the shade and sat there watching the children play. As the day progressed they walked around quietly and chatted with parents and trainers and it became clear that they were enjoying being on what was for them "the other side". We observed the extent to which many of our volun- 
teers used our football schools as a breathing space that offered them the opportunity of crossing over earlier frontiers.

It was on that occasion that we conceived our "twin-city" concept. From that day onward we made it mandatory that in order to organize an Open Fun Football School, one must link with friends from "the other side", so that each and every Open Fun Football School comprises children and adults from a minimum of two communities and three football clubs, who on a daily basis live apart due to ethnic, social or political conflict. Further the Open Fun Football Schools are to be organized by volunteer coaches - coaches who may have literally shot at each other during the war. Similarly, for the most part the children at the school are children of parents who were active during the war.

\section{..AND ANOTHER DEAL}

Another occasion that made a decisive difference to the way in which we built up the organization and its program happened during spring, 1999, when we had to prepare the year's Open Fun Football Schools. We planned a seminar for the on-boarding football school leaders, during which we had to introduce them to our concept, demonstrate our games and way of organizing the respective football schools, and finally we had to discuss the extent to which we could best use the year's football schools in the service of peace.

We did not have a lot of money at our disposal and since I had played football at the primary and secondary legues in Denmark and trained some of the country's best youth players, I planned to lead the seminar and to be the "expert" that could show, explain and tell them how to do it. I did not consider this task much further than that. For family reasons though, I unexpectedly was forced to take my daughter, Amalie (1 year) with me. Naturally, it was not possible to teach with a diapered child in my arms and consequently the seminar assumed an alternative form than was planned.

Thankfully, Amalie had set nap times so while she had her morning and afternoon naps and at night, I placed her on a blanket under the lectern while I took advantage of those nap times to say a few fleeting words on the topics that I had planned prior to leaving home. I was able to speak at most for 30 minutes at a time, after which I pointed to some of the leaders and requested that they prepare and conduct some of the games that I had planned during the periods, that Amalie was awake.

To my delight and surprise, the school leaders assumed responsibility for their own matters and I experienced how they, without hesitation, discarded most of my games and football technique sessions, either because the exercises were too difficult for the children or were not fun enough.

I quickly realized that I was not the expert here but rather it was them who were, and we decided on the spot that moving forward we would build up a corps of local instructors whose task it would be to adapt our special "funfootball" concept and develop the program. The concept was not football in the classic sense but rather a football related game that was to be new, fun, and creative and that had the aim of providing participants with good experiences together and ensure that the children enjoyed playing football.

Today we are 180 instructors, all from different backgrounds in 12 countries, and the past 10 years have offered us an incredible journey where, with the child at the center, we were able to develop "sport qualities". Together we de- 
veloped an informal platform with local societies where people from different backgrounds can meet and interact over common concerns: children - welfare - the future and develop football for children (see www.ccpa.dk/cc).

\section{PROGRESS IN DEVELOPING THE FOOTBALL SCHOOLS}

In 2001, Denmark's Ministry of Foreign Affairs informed of its interest in supporting our project but under the condition that we made the project a regional effort. The Ministry wanted us to start similar efforts in neighbouring countries to Bosnia. The football school program started taking shape, moving away from being a "personal" project to building the foundation for an association. We prepared an organizational and strategy development seminar during which our local instructors had to develop the mission, vision, strategic aim, etc. of the association.

The seminar was designed and facilitated by DBU's educational leader, Poul Gilling. 54 people attended and we had decided in advance that we would develop the association using narrative methodology, i.e. story telling.

In many ways it was a memorable seminar. As usual, we started by holding a little football competition during which the players were asked to switch teams after each match, encouraging everyone to play together...the so-called "Bon Bon" Cup. I then welcomed everyone. After dinner, Poul Gilling approached me and said, "Anders, we need to come to an agreement. When I take over the seminar tomorrow, you must remain silent. You can only speak to me during the breaks, and you must not get involved in the discussions. Your instructors are very authority compliant and there are too many who do not dare to say anything while you are present."

So here I was, supposedly the driving force and idea man behind the Open Fun Football Schools now with my hands tied. We had yet to build the foundation for the association for which I was the initiator and leader and now I'm told not to participate in the discussions? While discussions were ongoing about the association's vision, I was sent out of the room! That was hard to swallow. It was even less palatable when I was called in and the assembly proudly informed of the association's future vision (what we envisage but cannot achieve):

(a) we will be a movement in the region; and

(b) we will be a movement in the world!

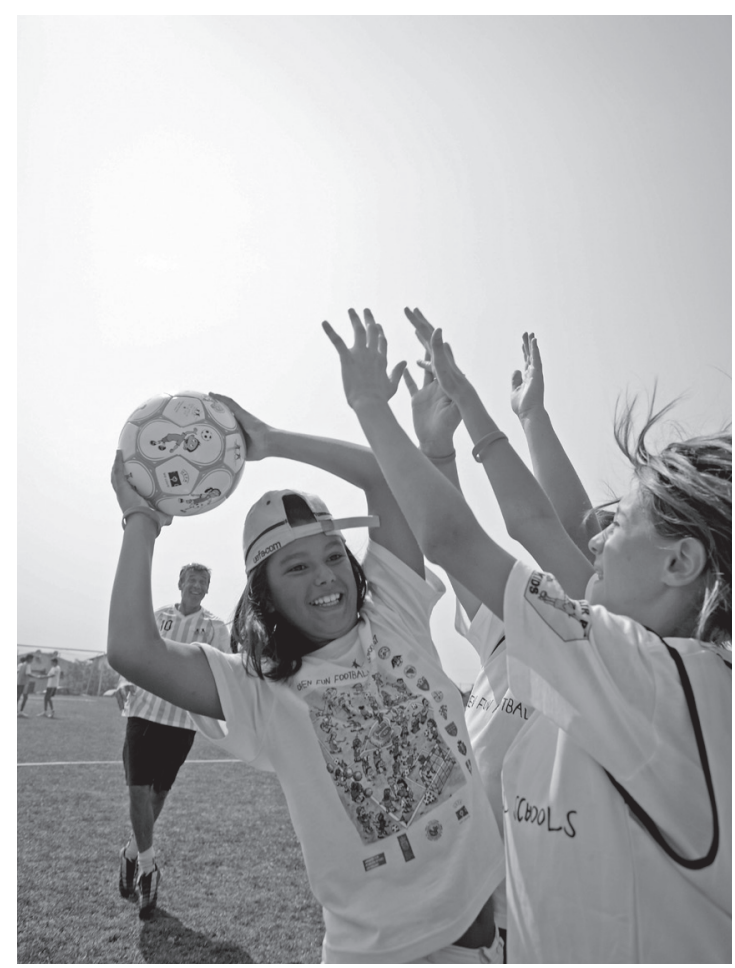

Kosovo 2007 (Photo: Kennteh Havgaard). 
I thought to myself "Wow! Shouldn't we first just plan this summer's football schools? “

A little later, the instructors constructed a model of the association using Lego bricks. I felt that it was a "cheap consultant gimmick" but later learned otherwise. Firstly, these adult men had never attempted to play with Lego before. It was great to see their joy and enthusiasm and to hear their laughter when they assembled the bricks in different ways. Secondly, it was overwhelming when they had to present their Lego models to each other. They had constructed houses with windows and doors that opened to the world enticing people to enter. There were various bridges and vehicles that were to be used to build bridges and initiate communication between people in conflict ridden areas.

There was also a very special model construction. It was a vehicle that could drive on land, sail and fly. The model children were placed around the vehicle next to their trainers who had antennae coming out of their heads so they could capture new ideas and communicate with children and friends from conflict ridden areas in other countries. On the "bridge" stood two model men, each carrying a suitcase. One of them was wearing an antenna on his head. $\mathrm{He}$ was an instructor. His suitcase was full of creativity, new and good ideas, communication and love for children and football. The other man had a tall black hat on his head - that was representative of me. My suitcase was full of donor money!

We laughed, told stories and sang. The tears rolled down our cheeks. Although the visions were lofty and the organizational models very abstract and impossible to replicate in ordinary organizational charts, our organization today is respectfully built on the backcloth of those models. We had developed a program and an association that today can be considered a movement in the region, driven by voluntary efforts and where the vital driving force is voluntary creativity, joy, energy and love for children and football.

The seminar taught me, amongst other things, that using story telling as a methodology is a brilliant tool when working on organizational development, and which we have had much use for along the way. It is especially useful when illustrating the purpose behind an activity and an association. When we story tell, we live through the stories and adopt them as our own. We tend to say that it is the stories that provide the Open Fun Football Schools their force.

Furthermore, the seminar taught me that if we wish to motivate volunteer leaders and trainers to assume responsibility for our program, it is useless to assume that we can just come over from Denmark and ask the volunteers to develop our visions, values, strategies and action plans and to do things "our way". It is our duty to draw people together from various population groups around something that they have in common - love for their children and their passion of playing football. Furthermore, we need to use our diverse activities to encourage the participants to join together in friendship.

\section{SPIN-OFFS}

Finally, let me state a couple of examples of some spin-off activities that have developed from our program and that we had not influenced but that were generated by our volunteer leaders and trainers.

In Armenia, our colleagues developed a school program themselves. They negotiated with the football association and the Armenian Ministry of Education for all children from $3^{\text {rd }}$ through $5^{\text {th }}$ grade as well as all students at the sports academy to have 32 hours football assigned to their 


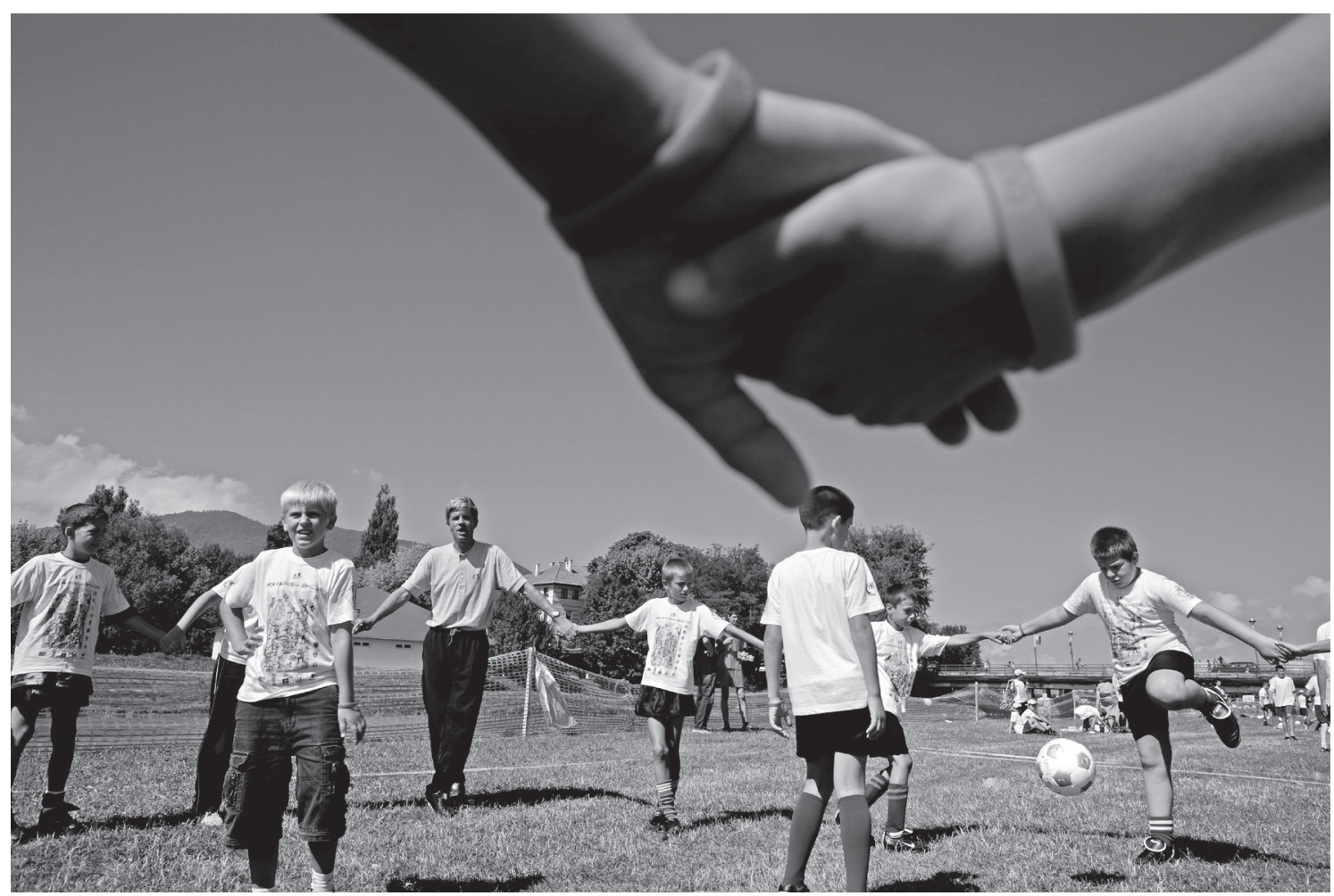

Sarajevo 2006 (Photo: Carsten Snejbjerg).

school schedules. More specifically, the children were to have 32 hours of a subject that, in the official academic plan was called 'Open Fun Football Schools' and that comprised play and sports pedagogy that is based on our principles and manuals! Today, the "Open Fun Football School Program" has been introduced and implemented in 1400 public schools in Armenia. Officially speaking, the schools project is not formally associated with Cross Cultures and our Open Fun Football Schools, however, the individuals supporting the school project are people associated with our association. The idea for the school project emanated from our workshops and the football school program itself and they use our logo, trainer's attire and manuals.

Our colleagues in Croatia similarly have their Open Fun Football Schools, under a campaign that uses the slogan of " 100 days for healthy lifestyle". The campaign is co-financed by Novo Nordisk and Media Lab (another medicare enterprise).

In Macedonia, using the approach of our fun football concept, our colleagues have carried 
out a project financed by the American Embassy, using the campaign slogan "Environment and Healthy Lifestyles", etc.

All of these activities are not part of the Open Fun Football Schools, in that the leadership of Cross Cultures has not been involved with the projects or have influenced them. In a similar manner, hundreds of smaller local projects exist that were developed and run by our volunteer leaders and trainers and have used our name, manuals and logo that probably are implemented in good faith. These are projects that are not necessarily within the Cross Cultures core but that build bridges and link people. They are all good examples of how the Open Fun Football Schools develop in meaningful ways and outside of our control and involvement. We delivered an idea and developed a program that today has impacted a mass and generated so much enthusiasm and proliferation in every way and that we do not control. With certainty we can claim that we were lucky to have received the opportunity to put into gear and developed an idea that in many ways has proved to be larger than our own association. 